\title{
P-33
}

\section{Puncak Alam Forest as Fungi Source of New Bioactive Metabolites}

\author{
Zuhra Bashir ${ }^{1, *}$, Jean-Frédéric Faizal Weber ${ }^{1}$, Sadia Sultan $^{1}$ and Mohamed Ashraf Bader ${ }^{2}$ \\ ${ }^{I}$ Atta-Ur-Rahman Institute for Natural Products Discovery (RiND), Faculty of Pharmacy, Universiti Teknologi MARA, \\ 43200 Puncak Alam, Selangor, Malaysia; ${ }^{2}$ Microbiology and Immunology Department, Faculty of Pharmacy, El- \\ Margeb University,Libya; E-mail: zuhrabasher@yahoo.com
}

Fungi have been an important source for producing wide range of secondary metabolites of widely different chemical structures, as well as biological activities. The objective of this study is to identify bioactive compounds from soil fungi isolated by selective chemotechiques.In this research, a total of 82 fungi were isolated from soil samples taken at three different depths $(5 \mathrm{~cm}, 25 \mathrm{~cm}$ and $40 \mathrm{~cm}$ ) collected from RiND biological reserve forest, UiTM Puncak Alam, Malaysia. The fungi were inoculated and fermented in presence or absence of toxic compounds. Each culture was extracted using ethyl acetate based on our standard operation procedure. The crude extracts were evaluated for preliminary screening of antimicrobial activity against pathogenic microorganisms using the MTT method. The antimicrobial effects of these crude extracts were only slightly less potent than standard antibiotics. The minimum inhibitory concentration (MIC) of the crude ethyl acetate extracts ranged from $0.19 \mathrm{mg} / \mathrm{mL}$ to $1.50 \mathrm{mg} / \mathrm{mL}$. The crude extracts were analyzed and fractionated by high performance liquid chromatography (HPLC). Some known bioactive compounds identified, including terrein (1) and kojic acid (2) by spectroscopic methods (LC/MS, NMR, UV/Vis) and comparison with data from literature.

Keywords: Antimicrobial, Terrein, Kojic acid, secondary metabolites, HPLC, NMR. 